\title{
A New Synthetic Method of Lavandulols
}

\author{
By Masanao Matsui and Akio Kobayashi \\ Department of Agricultural Chemistry, Faculty of Agriculture, \\ University of Tokyo
}

Received June 20, 1962 ,

\begin{abstract}
As an application of the reaction of alkyl halide with senecioate in liquid ammonia, a new synthetic method of lavandulol and isolavandulol was described.
\end{abstract}

In the previous papers ${ }^{1 \sim 3)}$, the reaction of various compounds with senecioate (1) in the presence of alkali metal amide has been described. Especially, in the recent one the authors reported that the alkyl halide easily reacts with senecioate in liquid ammonia and gives $a$-alkyl substituted acid in considerable yield. I.R. spectra and other experimental results established that the acid is a mixture of $a$-alkyl-a-isopropenylacetic acid (IV) and $a$-alkyl-a-isopropylidene acetic acid (VI) . Evidently the $\beta, \gamma$-unsaturated acid (IV) easily isomerizes to yield stable conjugated $\alpha, \beta$ unsaturated acid (VI) in the presence of basic catalyst. Therefore, the presence of $a$-alkyl-a-isopropenylacetic acid (IV) in the reaction mixture may be suggested that this is the first product from the reaction of alkylhalide with senecioate, and another product $a$-alkyl-a-isopropylideneacetic acid is secondary product rearranged from first one.

On this assumption the authors suggest a reaction mechanism explaining the production of acid mixture as follows:<smiles>CCCCCCCC(=O)C=C(C)C</smiles>

(I)<smiles>CCC(C)(C)CCC(=O)O</smiles>

(IIa)<smiles>[R]OC([R])=C(C)C</smiles>

(V) $R$; alkyl

(V) $\mathrm{R} ; \mathrm{H}$

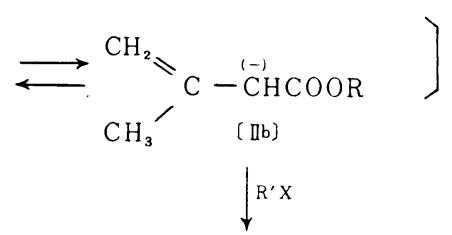<smiles>[134IH]</smiles><smiles>[R]C(C(=C)C)C(=O)O</smiles>

[II] $R$; alkyl [N] $\mathrm{R} ; \mathrm{H}$

FIG. 1.

1) M. Matsui, S. Okano, K. Yamashita, M. Miyano, S. Kitamura, A. Kobayashi T. Sato and R. Mikami, J. of Vitaminologo, 4, 178 (1958).

2) M. Matsui, K. Yamashita, M. Miyano, S. Kitamura, S. Okano, A. Kobayashi, T. Sato and R. Mikami, ibid., 4, 190 (1958). 685 (1960).
In the presence of alkali amide, carbanion of senecioate is produced and stabilized through limiting formulas (IIa) and (IIb). Then alkyl radical $\mathrm{R}^{\prime}$ attacks at $a$-position to yield $\alpha$-substituted- $\beta, \gamma$-unsaturated ester (III) 
which then isomerizes to $\alpha, \beta$-unsaturated ester (V) by the catalysis of potassium amide. The result that acidic fraction is, however, a mixture of (IV) and (VI) derived from hydrolysis of (III) and (V) shows that the reaction rate of such a basic catalized isomerization is much slower than that of alkylation to senecioate. According to this mechanism, (III) might be the only product, when less mole of potassium amide than the equivalent to reactants is used. In the presence of an excess of catalyst the ratio of (V) to (III) in the mixture will increase depending on the lavender oil by $\mathrm{H}$. Schinz et al. in 19424) and at the same time the structure was decided as 5-methyl-2-isopropenyl-4-hexene-1-ol, which is famous for its abnormal isoprene skeleton (3:4 isoprene link). Recently Soucěk ${ }^{5)}$ and Dolejs established its absolute configuration as R-type from the degradation product. The end double bond of lavandulol is easily rearranged to the inner position of the molecule and this isomer, 5-methyl-2-isopropylidene-4-hexene-1-ol, is called isolavandulol $(\mathrm{XIV})^{6}$.

The synthesis of lavandulols had been ac-

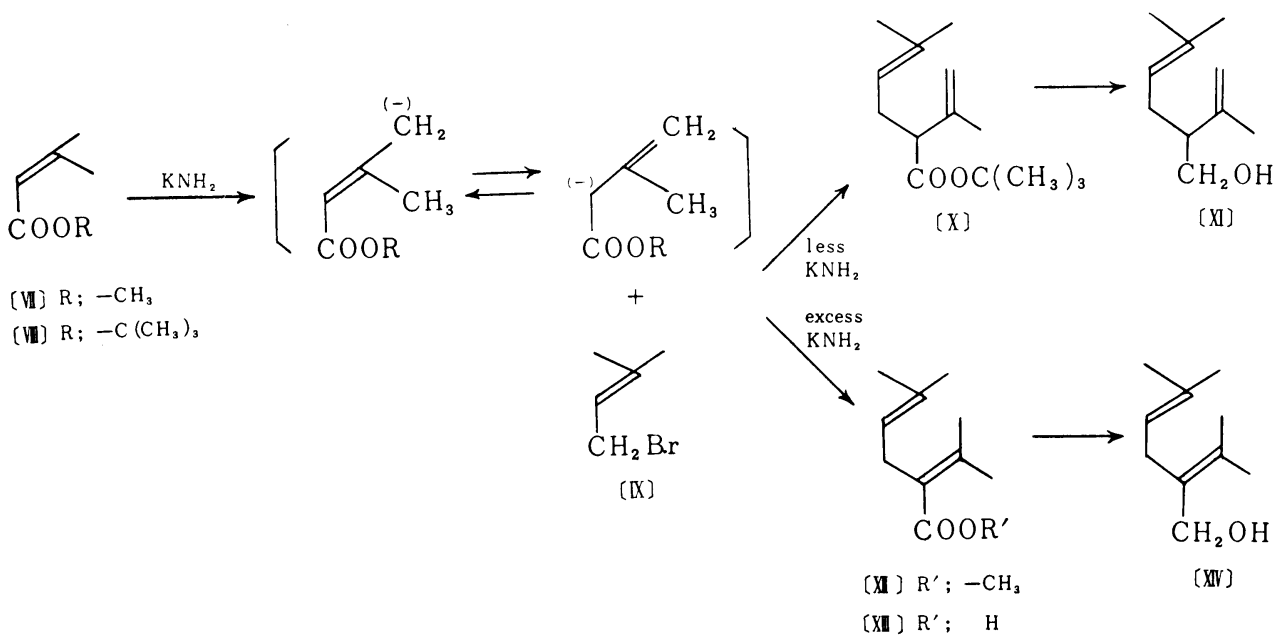

FIG. 2.

reaction time. In order to prove this assumption, the authors applied this reaction to the synthesis of lavandulol and isolavandulol, and succeeded in showing that the mole ratio of the basic catalyst is the determining factor between two isomers. Therefore, the present experiment has established a new synthetic method concerning the terpene having an abnormal isoprene skeleton, such as lavandulols, and at the same time has suggested the mechanism about alkylation of senecioate in liquid ammonia.

Lavandulol (XI) was isolated from French complished by the same investigators but the earlier method gave comparatively low yields and had to pass through many stages ${ }^{7 \sim 9)}$. In 1952, starting from isopropylidene malonate and 2-isopentenyl bromide, Kuhn and Schin $z^{10)}$ found a new method to snythesize lavandulylic acid as intermediate and obtained lavandulol in good yield. A new synthetic

4) H. Schinz und C.F. Seidel, Helv. Chim. Acta, 25, 1572 (1942).

5) M. Soucĕk and L. Dolejs, Collect. Czekoslov. Chem. Communs, 24, 3802 (1959)

6) H. Schinz und J.P. Bourquin, Helv. Chim. Acta, 25, 1591 (1942).

7) H. Schinz und G. Schppi, ibid., 30, 1483 (1947).

8) K. Brack und H. Schinz, ibid., 34, 2009 (1951) .

9) H. Grutter und H. Schinz, ibid., 35, 1656 (1952)

10) W. Kuhn und H. Schinz, ibid., 35, 2008 (1952). 
method of lavandulols described here involves only two steps as shown in Fig. II. As was expected, lavandulol and isolavandulol are selectively synthesized via lavandulylic and isolavandulylic esters (X), (XII), by use of less or excess equivalent mole of basic catalyst under the same condition for general alkylation of senecioate in liquid ammonia.

To synthesize lavandulol, tert-butyl senecioate is suitable because this ester is stable to alkali and will not be affected by ammonolysis to amide in liquid ammonia. The yield of alkylated ester $(\mathrm{X})$ is also better than any other alkyl esters; and this compound is reduced by lithium aluminum hydride to $d, l$ lavandulol (XI) without any purification. Based on potassium amide used as catalyst the total yield of lavandulol is 58 percent. However, methyl or ethyl senecioate is also applicable for synthesizing isolavandulol. In this case 3-alkylated senecioamide is present in the products but all of them are hydrolysed by alcoholic potassium hydroxide to isolavandulylic acid (XIII), which is esterified and reduced to isolavandulol. Calculated from methyl senecioate the total yield is 40 percent.

Physical constants of derivatives and absorption spectra data of lavandulols are shown and compared with $d$,l-lavandulol and iso- lavandulol in Table I synthesized by Schinz. From these data the authors can conclude that these two compounds are synthesized in their pure forms.

\section{EXPERIMENTAL}

tert-Butyl Lavandulylate. In a three necked flask equipped with an efficient stirrer, an outlet tube, and a dropping funnel is placed $100 \mathrm{ml}$ of liquid ammonia. The content is cooled to $-40 \sim-50^{\circ} \mathrm{C}$ in dry ice and acetone bath and $3 \mathrm{~g}$ of potassium metal and a catalytic amount of ferric nitrate are added in one portion. Stirring is started and when blue color of the metal in liquid ammonia disappears (in 20 30 min), $16 \mathrm{~g}$ of tert-butyl senecioate is added and after 30 minutes stirring, addition of $13 \mathrm{~g}$ of isopentenyl bromide dissolved in three times volume of dry ether is followed. Vigorous stirring is continued 2 hours more. After evaporation of ammonia the ether solution is poured onto ice-hydrochloric acid mixture. Ether layer is washed with $5 \%$ sodium hydroxide solution and water successively. After having been dried with sodium sulfate, ether is distilled off. The residual oil weighs $22 \mathrm{~g}$, which is distilled under reduced pressure. First fraction (unaltered tert-butyl senecioate) : b.p. $70 \sim 75^{\circ} \mathrm{C} / 15 \mathrm{~mm}$; yield, $8.0 \mathrm{~g} ; n_{\mathrm{D}}^{14}$ 1.4442. Second fraction (tert-butl lavandulylate): b.p. $105 \sim 110^{\circ} \mathrm{C} / 15 \mathrm{~mm}$; yield, $11.8 \mathrm{~g} ; n_{\mathrm{D}}^{14} 1.4492$.

$\boldsymbol{d}, \boldsymbol{l}$-Lavandulol. In a three necked flask equipped with stirrer, a dropping funnel and a reflux condenser protected with a calcium chloride tube $2.0 \mathrm{~g}$ of lithium aluminum hydride is dissolved in $100 \mathrm{ml}$ of dry ether. With stirring and cooling in an ice

TABLE I.

\begin{tabular}{|c|c|c|c|c|}
\hline \multirow[b]{2}{*}{$\begin{array}{l}\text { B.p. } \\
n_{\mathrm{D}}\end{array}$} & \multicolumn{2}{|c|}{$d, l$-Lavandulol } & \multicolumn{2}{|c|}{ Isolavandulol } \\
\hline & $\begin{array}{l}\text { Schinz et al. } \\
94 \sim 5^{\circ} \mathrm{C} / 12 \mathrm{mmHg} \\
1.4705\left(17^{\circ} \mathrm{C}\right) \\
117 \sim 118^{\circ} \mathrm{C}\end{array}$ & $\begin{array}{l}\quad \text { Authors } \\
78 \sim 80^{\circ} \mathrm{C} / 5 \mathrm{mmHg} \\
1.4690\left(18^{\circ} \mathrm{C}\right) \\
117 \sim 119^{\circ} \mathrm{C}\end{array}$ & $\begin{array}{l}\text { Schinz et al. } \\
107^{\circ} \mathrm{C} / 12 \mathrm{mmHg} \\
1.4837\left(17^{\circ} \mathrm{C}\right) \\
143 \sim 144^{\circ} \mathrm{C}\end{array}$ & $\begin{array}{l}\text { Authors } \\
100 \sim 110^{\circ} / 10 \mathrm{mmHg} \\
1.4812\left(12^{\circ} \mathrm{C}\right) \\
143^{\circ} \mathrm{C}\end{array}$ \\
\hline $\begin{array}{l}\text { Allophanate } \\
\text { 3,5-Dinitro } \\
\text { benzoate }\end{array}$ & $\begin{array}{l}117 \sim 118^{\circ} \mathrm{C} \\
75^{\circ} \mathrm{C}\end{array}$ & $73 \sim 75^{\circ} \mathrm{C}$ & - & 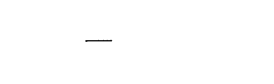 \\
\hline $\begin{array}{l}\text { I. R spectra }\left(\mathrm{cm}^{-1}\right) \\
\text {-OH }\end{array}$ & 3400,1050 & 3400,1037 & - & 3400,1000 \\
\hline$>\mathrm{a}=\mathrm{c}\langle$ & 1672.840 & 1670,835 & - & $1670, \quad 840$ \\
\hline $\mathrm{C}=\mathrm{CH}_{2}$ & 1647,892 & 1645,887 & & \\
\hline
\end{tabular}


bath, $9.0 \mathrm{~g}$ of tert-butyl lavandulylate dissolved in $50 \mathrm{ml}$ dry ether is added from a dropping funnel, then refluxed on a water bath for 2 hours with stirring. The mixture is cooled to $0^{\circ} \mathrm{C}$, decomposed by ethyl acetate and poured onto ice-hydrochloric acid mixture, and the water layer is extracted twice with ether. The combined ether layer is washed with $10 \%$ sodium hydroxide solution and water successively. After having been dried with anhydrous sodium sulfate the residual oil is distilled under reduced pressure. B.p. $78 \sim 80^{\circ} \mathrm{C} / 5 \mathrm{~mm}$. Yield, 5.1 g. $n_{\mathrm{D}}^{18.5}$ 1.4690 .

Allophanate. M.p. $117 \sim 119^{\circ} \mathrm{C}$ (recrystallised from ethanol-water). Anal. Found: C, 60.15; H, 8.21; N, 11.41. Calcd. for $\mathrm{C}_{12} \mathrm{H}_{20} \mathrm{O}_{3} \mathrm{~N}_{2}$ : C, 59.98; $\mathrm{H}, 8.39 ; \mathrm{N}$, $11.66 \%$.

3,5-Dinitrobenzoate. M.p. $73 \sim 75^{\circ} \mathrm{C}$ (recrystallised from ethanol-water). Anal. Found: C, 58.62; $\mathrm{H}$, 6.09; N, 8.13. Calcd. for $\mathrm{C}_{17} \mathrm{H}_{20} \mathrm{O}_{6} \mathrm{~N}_{2}: C$, 58.61; $\mathrm{H}$, $5.79 ; \mathrm{N}, 8.13 \%$.

Methyl Isolavandulylate. The apparatus and the procedure are the same as those described above, but the ratio of reactants to basic catalyst is changed. Methyl senecioate $(7.5 \mathrm{~g})$ and isopentenyl bromide $(9.5 \mathrm{~g})$ are allowed to react in the presence of $4.2 \mathrm{~g}$ of potassium amide (prepared from $3.0 \mathrm{~g}$ of potassium metal) for 4 hours and reaction mixture is left to standing overnight in liquid ammonia. After evaporation of ammonia and extraction with ether $8.7 \mathrm{~g}$ of residual oil is obtained. The oil is dissolved in $50 \mathrm{ml}$ of $10 \%$ ethanolic potassium hydroxide solution and refluxed for 2 hours. After cooling, the content is diluted with $100 \mathrm{ml}$ of water and extracted with ether before and after acidification. The second etherial extract is washed with water and the solvent is distilled off. The crude acidic oil is esterified with diazomethane in ether to give methyl isolavandulylate, which is distilled under reduced pressure. B.p. $110 \sim 120^{\circ} \mathrm{C} / 20 \mathrm{~mm}$. Yield, $5.8 \mathrm{~g}$.

Isolavandulol. The reduction of methyl isolavandulylate to alcohol with lithium aluminum hydride is the same as that of lavandulol. By use of $1.0 \mathrm{~g}$ of lithium aluminum hydride, $4.5 \mathrm{~g}$ of methyl ester affords $2.8 \mathrm{~g}$ of isolavandulol. B.p. $100 \sim 110^{\circ} \mathrm{C} / 10 \mathrm{~mm}$. $n_{\mathrm{D}}^{12} 1.4812$.

Allophanate. M.p. $144 \sim 145^{\circ} \mathrm{C}$ (recrystallised from methanol-water) . Anal. Found: C, 59.53; H, 7.83; N, 11.22. Calcd. for $\mathrm{C}_{12} \mathrm{H}_{20} \mathrm{O}_{3} \mathrm{~N}_{2}: \mathrm{C}, 59.98 ; \mathrm{H}, 8.39 ; \mathrm{N}$, $11.66 \%$. 